\title{
SUJEITOS DA DIVERSIDADE: AAGENDA LGBT NA EDUCAÇÃO DE JOVENS E ADULTOS
}

Roberto Catelli Jr

catelli.roberto@gmail.com

Ação Educativa

Michele Escoura

micheleescoura@gmail.com

Universidade de Campinas

RESUMO: Ao longo dos anos a educação de jovens e adultos foi se constituindo como espaço de inclusão e enfrentamento das desigualdades tanto no Brasil como no campo internacional, tal qual indicam os documentos das Conferências de Educação de Adultos (CONFINTEA). Neste artigo, destacamos o desafio da inclusão do grupo de pessoas LGBT, especialmente travestis e transexuais, na agenda de debate, pesquisa e ação para o movimento de defesa da modalidade. Analisamos os resultados de estudos qualitativos que mostram o grande processo de exclusão vivido pela população LGBT dos espaços escolares e a necessidade de trazermos novos dados de pesquisas qualitativas e quantitativas com o objetivo de reafirmar o lugar da EJA como estratégia fundamental para a garantia do direito humano à educação, incluindo-se o grupo LGBT.

PALAVRAS-CHAVE: Educação de jovens e adultos; inclusão social; LGBT.

\section{DIVERSITY AND THE LGBT AGENDA IN YOUTH AND ADULT EDUCATION}

ABSTRACT: Youth and adult education has proven to be a powerful tool in the fight for the inclusion of minorities and against inequality in Brazil and several other countries, as indicates the documents from the Conference of Adult Education (CONFINTEA). In this paper, the challenge to introduce the LGBT population, especially transgender individuals, into the core of new studies and actions towards the dissemination of the practice has been given special attention. Qualitative studies that make evident the exclusion of the LGBT population in the education system and the need to gather both quantitative and qualitative data have been analyzed as a means to reaffirm the role of EJA as a fundamental strategy to guarantee the human right to education.

KEYWORDS: Youth and Adults Literacy; social inclusion; LGBT. 


\section{Introdução}

O processo de institucionalização da Educação de Jovens e Adultos (EJA) no Brasil está vinculado à luta ao direito à educação ao longo da vida e à criação de uma modalidade de ensino que pudesse acolher sujeitos excluídos em contextos marcados por grande desigualdade social. A reinvindicação histórica dos movimentos sociais brasileiros para a criação de políticas de superação das desigualdades educacionais ecoou internacionalmente durante a VI CONFINTEA realizada em Belém em 2009 e estabeleceu como marco o caráter inclusivo da EJA.

Os indicadores sociais do século XX comprovam a exclusão de grande parcela da classe trabalhadora rural do direito à escolarização até os anos de 1970 no Brasil. Em 1980, 46,3\% da população rural com 15 anos ou mais era analfabeta e 16,8\% da população urbana (FERRARO, 2012). Ainda em 2014, 29,1\% da população rural e 6,3\% da população urbana era analfabeta (BRASIL, 2016). Nas últimas décadas do século XX, novos processos sociais e a emergência de nova dinâmica econômica, na qual ocorreram grandes migrações do campo para a cidade e desenvolvimento tecnológico que passou a exigir maior qualificação do trabalhador, atualizaram o perfil da demanda da EJA no país.

Seguindo acordos internacionais como a Declaração de Jomtien, ratificada por 150 países, como resultado da Conferência Educação para Todos, a partir dos anos de 1990, o governo brasileiro investiu na inclusão de um grande contingente de crianças à escola no Brasil, deixando para trás um passado, no qual muitas destas nem chegavam a iniciar o processo de escolarização (OLIVEIRA, 2007). Entretanto, programas de alfabetização ineficientes e a baixa adesão de jovens e adultos a cursos escolares presenciais para retomar os estudos fez com que ainda se acumulasse no país grande contingente de pessoas que não se alfabetizaram ou nem mesmo concluíssem seus estudos no nível fundamental. Juntam-se a essas ainda as/os jovens que iniciam seus estudos na atualidade, mas não o concluem, abandonando a escola por diferentes processos de exclusão. Basta lembrar que, em 2013, conforme a Pesquisa Nacional por Amostra de Domicílios (PNAD, IBGE, 2013), ainda 47\% das/os jovens com 19 anos não tinham concluído o ensino médio.

Este novo contexto fez da educação de jovens e adultos no século XXI uma modalidade que atende adultos e idosos, mas também um grande contingente de jovens excluídas/os da escola, ainda quando crianças ou adolescentes. Pressionados pelas demandas da vida social e do mercado de trabalho, parcela significativa destas/es buscam 
concluir a educação básica na EJA. Estas mudanças vêm exigindo também redefinições nas próprias formas de se pensar a EJA e suas formas de organizar o currículo, uma vez que os sujeitos e suas demandas estão em processo de transformação.

Mas, para além das/os jovens, outros perfis de estudantes são potenciais demandantes da EJA a se somar nos bolsões da população com 15 anos ou mais, sem completar a educação básica. Dentre eles, está o público LGBT. Desde os anos de 1980, sob impulso de diferentes movimentos sociais alinhados às reinvindicações por reconhecimento identitário, lésbicas, gays, bissexuais, travestis e transexuais têm emergido no cenário político nacional e fortalecido a luta pela expansão de direitos fundamentais ${ }^{1}$.

Embora, na última década, avanços da pauta LGBT tenham se tornado perceptíveis, nas políticas públicas, seja pelo lançamento do Programa Brasil sem Homofobia (em 2004), a realização das duas Conferências Nacionais LGBT (em 2008 e 2012) ou a aprovação do casamento civil de pessoas do mesmo sexo, pelo Supremo Tribunal Federal (em 2013), as ações para promoção de igualdades educacionais ainda são muito limitadas. Em um país ainda marcado pela discriminação de gênero e respaldado em amplo espectro por valores religiosos tradicionais, o direito à educação de pessoas LGBT têm sido constantemente colocado em risco. Os três níveis de governo não têm conseguido realizar esforços para mapear, estatisticamente, os efeitos da discriminação no ambiente escolar, mas cada vez mais pesquisas qualitativas indicam trajetórias de vidas marcadas por preconceito, abandono ou expulsão do ambiente escolar, sem que se tenha a perspectiva de retornar ao mesmo, uma vez que o contexto social impõe, na maioria das vezes, uma situação de vulnerabilidade a esses grupos. Neste texto, procuraremos evidenciar que, estando fora da escola desde a infância ou adolescência, lésbicas, gays, bissexuais, travestis e transexuais podem encontrar na EJA uma possibilidade de reinserção na vida escolar, em uma perspectiva inclusiva. Em contrapartida, trazem para a EJA uma nova agenda de luta política.

\footnotetext{
${ }^{1}$ Atualmente, a sigla LGBT refere-se a "Lésbicas, Gays, Bisexuais, Travestis e Transexuais". Assim como é recente a visibilidade dos movimentos sociais em defesa dos direitos desse grupo, é recente também essa última formulação da sigla. Foi somente durante a $1^{\text {a }}$ Conferência Nacional de Gays, Lésbicas, Bissexuais, Travestis e Transexuais, em 2008, que a letra "L" veio à frente da sigla GLBT como resolução a antigas demandas do movimento de mulheres lésbicas. Embora esta tenha sido a nomenclatura firmada pelo movimento, ainda é possível encontrar o uso de "movimento gay" ou "grupo GLS (Gays, Lésbicas e Simpatizantes)", como expressões populares para se referir a pessoas LGBT. É possível também encontrar o diminutivo "movimento trans" ou "pessoas trans", como forma de nomenclatura para o movimento específico de travestis e transexuais.
} 
Neste artigo, primeiro retomaremos aspectos do processo histórico de institucionalização da EJA, para referendá-la como espaço de inclusão e o acolhimento de sujeitos excluídos do processo de escolarização. Percorreremos análises qualitativas que sinalizam a exclusão de pessoas LGBT, especialmente de travestis e transexuais, das escolas voltadas a crianças e adolescentes, destacaremos a ausência de indicadores de evasão escolar provocada por discriminação de gênero e, em seguida, discutiremos como tais discriminações apresentam-se como um importante eixo que precisa ser levado em consideração, para identificarmos o público-alvo da EJA nos dias atuais.

Nosso objetivo é reafirmar o lugar da Educação de Jovens e Adultos como estratégia fundamental para a garantia do direito humano à educação e evidenciar uma nova agenda de debate, pesquisa e ação política para o movimento de defesa da EJA: se reconhecer como espaço de inclusão para pessoas LGBT. A EJA consolidou-se ao longo dos anos, como uma educação para os sujeitos trabalhadores do campo e da cidade. Nos tempos atuais, somam-se a esses/as jovens, que não necessariamente estão incluídos no mercado de trabalho, mas foram excluídos da escola, assim como o público LGBT, que pode vir a ter a EJA como espaço de inclusão social.

\section{A EJA como espaço de acolhimento de sujeitos historicamente excluídos}

Ao longo do século XX e adentrando o século XXI, verificamos que as motivações para fazer avançar a educação de jovens adultos tiveram diferentes tônicas e significados, se levarmos em conta os documentos produzidos pelas Conferências Internacionais de Educação de Adultos (CONFINTEA) ${ }^{2}$.

A primeira CONFINTEA, ocorrida em 1949, em Elsinore, na Dinamarca, reconhecia como grande objetivo central a promoção do que denominavam de entendimento internacional, em um mundo que ainda vivia as consequências da Segunda Guerra Mundial (IRELAND, 2012). Neste contexto, o sentido da EJA como espaço de inclusão não se colocaria tal qual ocorreria no século XXI. Entretanto, já considerava que a educação de adultos deveria incentivar o estudo de questões controversas, estabelecendo

\footnotetext{
${ }^{2}$ Entre 1949 e 2009, ocorreram seis Conferências Internacionais de Educação dos Adultos (CONFINTEA), sendo uma a cada 12 anos. A conferência organizada pela Unesco é responsável pela indicação das grandes diretrizes para a educação de adultos, em nível internacional.
} 
o direito das pessoas discordarem, de modo a garantir a liberdade de pensamento como base para um entendimento internacional.

A segunda CONFINTEA, ocorrida em Montreal, em 1960, trazia pela primeira vez a defesa de que a educação das mulheres deveria receber especial atenção, uma vez que a baixa escolaridade e o analfabetismo entre as mulheres eram muito superiores aos dos homens, em muitas partes do mundo. Já a Conferência seguinte, de 1972, realizada em Tóquio, traria pela primeira vez com maior força o conceito de "educação ao longo da vida", entendendo que todos deveriam ter oportunidades de aprendizagem em qualquer momento de suas trajetórias pessoais. Na V CONFINTEA, realizada em Hamburgo, a ideia de que a educação de adultos refere-se a uma educação ao longo de toda a vida ganharia força, destacando-se que a educação teria um caráter de intervenção social, para satisfazer as necessidades básicas de aprendizagem (IRELAND, 2012). Surge em Hamburgo também a ideia de que vivemos em uma sociedade multicultural, na qual os estudos devem ser garantidos para todos, reconhecendo a diversidade cultural. $\mathrm{Na}$ perspectiva de fortalecimento da democracia, a V CONFINTEA coloca a necessidade de haver equidade entre os gêneros e maior empoderamento das mulheres. Considera, ainda, que os signatários comprometeram-se a desenvolver "programas de educação que propiciem a compreensão das relações homem-mulher e da sexualidade humana em todas as dimensões" (IRELAND, 2012, p. 223).

Era a primeira vez que um documento internacional, assinado por 130 estados membros da Unesco, incluía de maneira mais efetiva a preocupação de fazer da educação de jovens e adultos um espaço de intervenção social que poderia ser parte do processo de busca de maior equidade e de fortalecimento da democracia, incluindo-se aí as questões de gênero e, de maneira ainda um tanto obscura, o que se denominou como "sexualidade humana em todas as suas dimensões".

$\mathrm{Na}$ VI CONFINTEA, realizada em Belém, em 2009, o documento final da Conferência, denominado Marco de Ação de Belém, explicita o sentido inclusivo da EJA. Em um dos itens do documento, declara-se que:

\footnotetext{
A educação inclusiva é fundamental para a realização do desenvolvimento humano, social e econômico. Preparar todos os indivíduos para que desenvolvam seu potencial contribui significativamente para incentivá-los a conviver em harmonia e com dignidade. Não pode haver exclusão decorrente de idade, gênero, etnia, condição de imigrante, língua, religião, deficiência, ruralidade, identidade ou orientação sexual, pobreza, deslocamento ou encarceramento. É particularmente importante combater o efeito cumulativo de carências múltiplas. Devem ser tomadas medidas para aumentar a motivação e o acesso de todos (UNESCO, 2010, Artigo 15).
} 
Mesmo, havendo a compreensão mais ampla da educação de adultos como espaço de inclusão de diferentes grupos, a maior tônica se dá em relação às mulheres e aos povos indígenas ${ }^{3}$, sem explicitar ou aprofundar o sentido de exclusão relacionado a orientação sexual ou identidade de gênero ${ }^{4}$.

Entretanto, no âmbito do problema suscitado neste artigo, cabe ressaltar que a VI CONFINTEA, realizada em um período de afirmação de ampliação de direitos das diferentes identidades de gênero e orientação sexual em muitos países democráticos, trouxe pela primeira vez, de maneira mais explícita, a preocupação em fazer da educação de jovens e adultos espaço de inclusão para a população LGBT.

No Brasil e em toda a América Latina, deve-se destacar a presença da educação popular, especialmente a partir dos anos de 1950, intimamente ligada à trajetória dos movimentos populares na América Latina. Suas propostas educativas têm um forte significado político, colocando em pauta a ideia de transformação social e emancipação dos povos oprimidos. Nessa direção, desenvolve propostas pedagógicas para trabalhadores urbanos e rurais, povos indígenas e outros grupos que sofrem qualquer tipo de opressão, no âmbito da sociedade capitalista.

No Brasil, autores como Paulo Freire tornaram-se ícones da construção de uma proposta educacional, que tem como foco a emancipação dos sujeitos e a transformação social, com especial atenção às populações vítimas da opressão e as reconhecendo como demandantes da educação de jovens e adultos.

\footnotetext{
${ }^{3}$ Deve-se destacar também a abrangência do documento, que procura identificar a educação de jovens e adultos para todos os sujeitos historicamente excluídos, tais como as mulheres, os povos indígenas, os encarcerados, populações rurais, migrantes e pessoas com necessidades especiais.

${ }^{4}$ São consideradas "orientações sexuais" a forma como indivíduos balizam seus desejos afetivos e sexuais, ou seja, como orientam seus olhares e gostos quando projetam expectativas de relações afetivas e sexuais: "heterossexuais", quando sentem atração por pessoas do gênero oposto ao seu, "homossexuais", quando se atraem por pessoas do mesmo gênero, "bissexuais", quando se relacionam com pessoas tanto do mesmo gênero como do gênero oposto e "assexuais", quando não sentem atração sexual. Discriminações em relação à orientação sexual, neste caso, referem-se àquelas sofridas por gays, lésbicas e bissexuais, que se relacionam afetiva e sexualmente com pessoas do mesmo sexo e confrontam a regra socialmente estabelecida da heterossexualidade compulsória (que prevê que o único desejo legítimo e aceitável seria por pessoas do gênero oposto). Já "identidade de gênero" é a expressão usada para se referir à forma como os indivíduos constroem sua autoimagem e como se projeta para o mundo ao seu redor, portanto, como se "identifica". Em nossa cultura, há a expectativa de que pessoas que nasçam com uma genitália "feminina", por exemplo, também construam uma identidade feminina e que se identifiquem como mulheres. Entretanto, há pessoas que deslocam esses referenciais e constroem para si identidades que não seguem à prescrição de seu sexo, ou seja, que nascem com um órgão genital, mas não se reconhecem como pertencente ao gênero previsto a partir dele. São os casos de "pessoas trans": travestis, mulheres transexuais e homens trans. A discriminação decorrente à "identidade de gênero" é aquela que parte do pressuposto de que há uma natureza única das identidades e que ninguém pode ter uma identidade diferente daquela do seu sexo, que reduz todas as possibilidades de identificação que alguém pode ter ao seu registro biológico.
} 
Em 2013 foi formulado no Brasil o Marco de Referência de Educação Popular para as Políticas Públicas (BRASIL, 2014), que procura recuperar e atualizar o significado da educação popular, reconhecendo seu potencial para ser um marco teórico e político para as políticas públicas. Nesse contexto, faz referências às iniciativas educacionais, que se relacionaram diretamente com populações historicamente vulneráveis, como mulheres, camponeses, indígenas e o grupo LBGT. Entretanto, no que se refere a este grupo, o documento não faz mais do que uma menção sobre a necessidade de serem considerados.

Em outra perspectiva, Carreira (2014) defende que se possa no Brasil compreender a educação de jovens e adultos como um espaço de ação afirmativa contra desigualdades de gênero e raça. A autora destaca que a questão racial e de gênero ainda têm baixa visibilidade nas políticas para educação de jovens e adultos e, em entrevistas que realizou com gestores públicos relacionados à educação de jovens e adultos, em especial da Secretaria de Educação Continuada, Alfabetização, Diversidade e Inclusão (SECADI), constatou que

\begin{abstract}
A situação dos rapazes negros, grupo social mais excluído do ensino regular, que adentra a EJA com intensidade nas últimas duas décadas, não é abordada espontaneamente como questão de gênero e raça por nenhum dos entrevistados. Destaca-se também a total ausência nos depoimentos de reconhecimento da EJA como modalidade que atende lésbicas, gays, travestis, transgêneros e transexuais excluídas/os do ensino regular (CARREIRA, 2014, p. 209).
\end{abstract}

Com isso, para a autora, é necessário apostar na educação de jovens e adultos como espaço de políticas afirmativas que avancem na direção de uma educação de qualidade para todas/os e que possa

\footnotetext{
superar a herança racista e a histórica tolerância para com as desigualdades que ainda marcam a sociedade e o Estado brasileiros, sejam elas de gênero, renda, região, campo/cidade, idade, sexualidade, de ciências etc. É apostar em políticas que efetivamente garantam o direito humano à educação para todos e todas. Nessa perspectiva, a EJA constitui uma das faces mais explícitas do desafio educacional e da afirmação dos direitos humanos do país (CARREIRA, 2014, p. 209).
}

Cabe mencionar ainda que, no Brasil do século XXI, a educação de jovens e adultos vem cada vez mais se caracterizando como um espaço da diversidade. Encontramos em escolas alunos/as com necessidades especiais, jovens em liberdade assistida, migrantes de diversos lugares, enfim, cada vez mais, a EJA se coloca como uma educação do/a trabalhador/a, mas também como espaço que abriga todas/os aquelas/es 
que acabam por ser alijadas/os da escola para crianças e jovens, em um sistema social claramente excludente e desigual.

Em 2015, uma experiência inédita, mas de alcance ainda bastante limitado, desenvolveu-se em São Paulo e vem trazer luz sobre a inserção da população LGBT na escola e o papel da EJA como espaço de inclusão. Trata-se do Programa Transcidadania, que foi construído como política intersetorial, envolvendo a Secretária de Direitos Humanos, Educação e Saúde da Prefeitura Municipal de São Paulo. A prefeitura de São Paulo estabeleceu um canal entre a Educação de Jovens e Adultos e as políticas para a população travesti e transexual, ao estabelecer o retorno à escola e a elevação de escolaridade desta população, por meio da EJA como uma das prioridades Programa. Entre 2015 e 2016, duzentas/os participantes do Programa voltaram aos bancos escolares e conquistaram apoio institucional (inclusive com recebimento de bolsa de estudos e trabalho) para terem garantido o direito à educação. A proposta alia diferentes secretarias municipais, para implementar atividades de elevação de escolaridade, qualificação profissional, formação em direitos humanos e atendimento de saúde. O objetivo é romper com o ciclo estrutural de vulnerabilidade da população travesti e transexual e abrir a estas pessoas a oportunidade de trilhar novas trajetórias pessoais ${ }^{5}$.

\section{Impasses sobre a questão de gênero na escola: permanências e resistências}

A segunda metade do século XX foi marcada por movimentos por direitos civis e reconhecimento identitário. Seja nacional e internacionalmente, os movimentos de mulheres, de negras/os ou, mais recentemente, os LGBT trouxeram um novo ânimo para as lutas sociais e mobilizações de rua. Nos Estados Unidos da América, a Rebelião de Stonewall, em 1969, é indicada como um dos principais marcos do princípio da organização de lésbicas, gays, bissexuais, travestis e transexuais em prol de igualdade civil. No Brasil, a mobilização LGBT inicia-se ao passo da reabertura política dos finais dos anos de 1970 e início dos anos de 1980 e é caracterizada pela atuação de dois

\footnotetext{
${ }^{5}$ O Programa, em andamento no momento da produção deste artigo, não tinha conseguido ainda registrar os resultados que já começam a surgir, com o evidente empoderamento de pessoas que não tinham acesso à educação e se viam excluídas de novas possibilidades. A primeira turma de formatura, em novembro de 2015 , mostrava pessoas que vislumbravam novos projetos pessoais. Em verdade, tinham saído do contexto de isolamento e exclusão, sendo a educação em articulação com as políticas intersetoriais um caminho bemsucedido para tanto.
} 
importantes coletivos: o Grupo Somos em São Paulo e o Grupo Gay da Bahia, em Salvador.

A partir dos anos de 1990, o conceito "gênero" ganha força nos círculos acadêmicos no Brasil e assistimos ao fortalecimento teórico das discussões feministas e LGBT nos anos que se decorrem. Judith Butler é traduzida para o português na década seguinte e, a partir de suas teorias, solidifica-se ainda mais o diálogo entre teoria e movimentos sociais que, desde 1997, já organizavam aquela que seria considerada a maior manifestação em luta dos direitos LGBT do mundo: a Parada do Orgulho LGBT de São Paulo. Com os movimentos organizados, as discussões voltadas aos direitos civis LGBT foram ganhando cada vez mais espaço institucional e reconhecimento gradual nas políticas públicas. Mas, na mesma velocidade que leis contra discriminações começaram a ser promulgadas, uma onda reativa e contrária às demandas dos movimentos LGBT também começou a ser organizada.

A tentativa de implementação do material "Escola sem homofobia", em 2011, pelo Ministério da Educação, que buscava apresentar materiais de formação para os profissionais da educação combaterem a discriminação LGBT nas escolas, foi fortemente contrariada e boicotada por setores conservadores da sociedade que, naquele ano, conseguiram vetar sua distribuição ${ }^{6}$. As discussões relativas às demandas por igualdade de gênero vieram, desde então, sofrendo forte recusa de setores religiosos organizados e inseridos nas esferas legislativas e executivas federais, estaduais e municipais. Tais setores têm travado uma cruzada contra qualquer tentativa de política pública que abarque este tema nos últimos três anos e, em 2014, atacaram novamente as discussões na educação. O texto final do Plano Nacional de Educação, que tangenciará a política educacional pelos próximos 10 anos, foi aprovado e sancionado após a extinção do termo "gênero" de suas metas, pelo legislativo, contrariando as deliberações da Conferencia Nacional de Educação. E, no ano seguinte, foi a vez das câmaras municipais e assembleias estaduais virarem palco de uma batalha pela retirada do conceito dos planos locais de educação.

O movimento LGBT, o movimento de mulheres, o de defesa pelo direto à educação e setores da academia mobilizaram-se e assistiram com perplexidade à distorção da discussão sobre gênero consolidada no país nos últimos trinta anos. No outro lado, bases eclesiais da igreja católica somaram-se às comunidades pentecostais para desenhar

6 O material "Escola sem homofobia" pode ser acessado pelo endereço eletrônico <http://revistaescola.abril.com.br/pdf/kit-gay-escola-sem-homofobia-mec.pdf>. Acesso em: 28 mar. 2016.

Olh@res, Guarulhos, v. 4, n. 1, p. 226-245, maio 2016. 
um cenário de cruzada contra o conceito de gênero. Aos poucos, o medo produzido pelos setores religiosos da sociedade ganhou uma dimensão antes pouco imaginada e, em efeito dominó, o conceito de gênero foi retirado dos desenhos das políticas públicas, principalmente dos planos municipais de educação, que se encontravam em processo de construção.

\subsection{Gênero na EJA}

Gênero, tal como ganhou força nos anos 1990, é um conceito referido às construções sociais que definem os limites entre as feminilidades e as masculinidades (SCOTT, 1990). É um termo cunhado a partir dos referenciais da linguística, para dizer que há elementos na nossa constituição, enquanto mulheres e homens que obedecem a regras histórica e socialmente forjadas, ou seja, que elementos daquilo que consideramos como sinais de feminilidade ou de masculinidade surgem a partir de contextos sociais bastante específicos e, portanto, não podem ser generalizados como elemento biológico da espécie humana.

Desde o início do século XX, pesquisas vêm mostrando como comportamentos, gostos, expectativas ou sonhos entre mulheres e homens são derivados de um intenso processo de socialização que varia de acordo com a diversidade de contextos culturais (MEAD, 2003; MAUSS, 2003). Meninas sentam de pernas fechadas porque são ensinadas a se sentarem de pernas fechadas, não porque algum gene ou hormônio produza esse efeito em seus corpos. Homens escondem suas lágrimas, porque aprenderam que meninos não podem chorar e, muitas vezes, foi sua própria professora quem lhes deu essa lição (ESCOURA, 2012).

Mas, além de nossa sociedade nos ensinar que alguns comportamentos devem ser distintos entre homens e mulheres, muitas vezes estabelece-se uma relação de hierarquia entre eles/as. O movimento feminista vem há várias décadas denunciando as relações de poder que conferem à feminilidade um status inferior nas dinâmicas sociais e, deste debate, desigualdades sofridas pelas mulheres ressoam diretamente na exclusão de muitas alunas do sistema de ensino. Neste ponto, podemos citar as discussões sobre as meninas que engravidam ainda no período escolar e se vêm obrigadas a abandonar os estudos, quando não há oferta de creches para suas crianças ou turmas de EJA abertas no mesmo horário letivo em que suas crianças estão na creche; o ideal de masculinidade associado ao trabalho, que leva muitos meninos a sair cedo da escola para ajudar no sustento das 
famílias; contextos de violência doméstica, em que mulheres estão em relações abusivas e são proibidas de frequentar escolas; ou até mesmo quando pensamos em quanto a desvalorização da profissão docente está intimamente ligada ao seu passado associado à feminilidade, como uma “profissão de mulher" e que, portanto, não precisaria ser tão bem remunerada (LOURO, 2004). Todas essas formas de exclusão ou desigualdade escolar são derivadas das hierarquias de gênero (AÇÃO EDUCATIVA \& CARREIRA, 2011) ${ }^{7}$.

E a desigualdade de gênero pode colocar em risco o direito à educação não apenas de mulheres. Um ideal de masculinidade baseado na insubordinação e agressividade, recorrente em muitos contextos socioculturais brasileiros, soma-se à dimensão do racismo institucional e leva muitos meninos a assumir uma postura violenta no contexto escolar. Tal comportamento não condiz com a representação ideal de "bom aluno", baseado em princípios de capricho e disciplina (comportamentos tidos como mais femininos) e os colocam em conflito direto com as normas que balizam o sucesso escolar (CARVALHO, 2004). Este também é um perfil de sujeito que tem cada vez mais demandado a EJA em todo país.

Sentar-se de pernas fechadas, não chorar ou ser agressivo são exemplos simples de comportamentos que, em nossa sociedade, foram transformados em sinais que demarcam se uma pessoa é feminina ou masculina. Partimos do pressuposto de que é "natural" que uma pessoa nascida com uma genitália feminina adquira trejeitos femininos e, de modo oposto, que uma pessoa com genitálias masculinas se expresse por comportamentos masculinos. Entretanto, essa idealização nem sempre obedece à lógica socialmente esperada, ou à chamada matriz de inteligibilidade de gênero (BUTLER, 2003).

O modo como uma pessoa se vê e busca ser reconhecida socialmente, se feminina ou masculina, depende de sua identidade de gênero, que não é necessariamente definido pelo aspecto biológico nem é automaticamente puro reflexo do órgão sexual da pessoa, como os códigos da nossa sociedade querem nos fazer acreditar. Muitas pessoas podem nascer com um registro sexual masculino e ter uma identidade feminina ou, ao contrário,

\footnotetext{
${ }^{7}$ Abramovay et al (2015) em pesquisa sobre juventude na escola fornece alguns dados que ilustram tais desigualdades. O perfil da EJA continua sendo de estudantes jovens trabalhadores. De sua amostra em todo território nacional, ela destacou que entre as/os estudantes da EJA, 55\% estudam e trabalham ao mesmo tempo. Sendo desses, $45 \%$ mulheres e $54 \%$ homens, e $66 \%$ trabalhando por 8 horas ou mais por dia. Em relação às mulheres que estão na EJA, é notável o dado que $56 \%$ delas tenham filhos, em contrapartida aos $22 \%$ dos estudantes homens da modalidade. E $12 \%$ delas apontam a necessidade de cuidar dos filhos e da casa como principal motivo para parar de estudar, enquanto este é um problema para apenas $7 \%$ dos homens.
} 
nascer com uma vagina e ter uma identidade masculina. Travestis e transexuais são essas pessoas em trânsito: que se reconhecem a partir de uma identidade de gênero diferente daquilo que a sociedade esperaria a partir de seu órgão genital e, então, produzem uma nova corporalidade para si.

Entretanto, desafiar as normas de gênero tradicionalmente postas em nossa sociedade não é uma tarefa fácil. Em 2012, diferentes canais de difusão de informações noticiaram com entusiasmo a primeira travesti ter alcançando o título de doutorado: Luma Andrade obteve o título de doutora em Educação pela Universidade Federal do Ceará, defendendo tese sobre a presença de travestis nas escolas. Se por um lado um clima de novidade instalava-se por conta da "primeira travesti doutora no Brasil", por outro lado, a surpresa gerada pela notícia desvelava o contexto generalizado de exclusão de travestis, do sistema escolar. Afinal, por que nos surpreendermos com uma travesti alcançando um dos mais altos graus de escolaridade?

Em pesquisa nacional sobre Juventudes e Sexualidade, publicada em 2004, a UNESCO reconhecia o ambiente escolar como espaço marcadamente violento e hostil para pessoas LGBT (Lésbicas, Gays, Bissexuais, Travestis e Transexuais) no Brasil. Para os meninos participantes da pesquisa, em uma classificação de ações consideradas mais violentas, "bater em homossexuais" aparece apenas em $6^{\circ}$ lugar, considerada como uma ação menos grave do que usar drogas ou portar armas, por exemplo. Quando perguntados sobre quais pessoas eles não gostariam de ter como colegas de classes, $25 \%$ dos entrevistados, em geral, indicam repulsa às pessoas identificadas como homossexuais ${ }^{8}$. De modo ainda mais alarmante, quando a mesma questão é colocada aos alunos homens na cidade de São Paulo, a possibilidade de ter um colega homossexual é rejeitada por 40,9\% deles (ABRAMOVAY et al., 2004).

Para atualizar este debate, a pesquisadora retomou a discussão com grupos de jovens estudantes da EJA, do Ensino Médio e do Programa ProJovem Urbano em todo o país e chegou em resultados ainda semelhantes, uma década depois. 22,6\% dos estudantes do Ensino Médio não querem uma pessoa LGBT como colega de turma, sendo mais agravante a rejeição por travestis, recusadas por 8,3\% deles. Mas quando esses dados são vistos pela variável de gênero o número aumenta: os meninos se mostram como os maiores discriminadores de gênero e 31,3\% deles recusam um colega de classe LGBT,

\footnotetext{
${ }^{8} \mathrm{Na}$ ocasião, o termo "homossexuais" foi usado de forma genérica para aquilo que atualmente denominase "LGBT". A discriminação contra pessoas travestis e transexuais estava abarcada no termo "homossexuais", não havendo uma coleta que especificasse a discriminação.
} 
enquanto 8,1\% das meninas demonstram rejeitar esse público (ABRAMOVAY et al., 2015).

Se de modo geral é possível identificar uma expressiva rejeição a todo público LGBT, no ambiente escolar, é preciso destacar que alguns sujeitos tendem a ser mais discriminados do que outros, como vimos no caso das travestis, na pesquisa acima, ou que a violência exercida contra eles/elas assume contornos específicos. Isso significa que a violência sofrida por uma lésbica pode ser muito diferente daquela sofrida por um homem trans, ou um garoto gay e, por isso, denominações específicas têm sido atribuídas às situações de violência: "transfobia" para casos de violência contra travestis e transexuais; "lesbofobia" para discriminação às mulheres que se relacionam afetiva e sexualmente com outras mulheres; e "homofobia" para homens que se relacionam afetiva e sexualmente com outros homens.

De acordo uma pesquisa realizada em 2009, pela Fundação Instituto de Pesquisas Econômicas (FIPE), em um levantamento realizado em 500 escolas, 26,6\% dos/as alunos/as entrevistados/as concordaram com a afirmação "Eu não aceito a homossexualidade"; 25,2\% concordaram com "Pessoas homossexuais não são confiáveis"; $23,2 \%$ com "A homossexualidade é uma doença"; $21,1 \%$ com "Os alunos homossexuais não são normais" e 17,7\% com “Os alunos homossexuais deveriam estudar em salas separadas" (MAZZON, 2009).

O relatório da pesquisa da UNESCO destaca que as práticas homofóbicas são comuns no ambiente escolar e que, inclusive, nas escolas a discriminação contra pessoas LGBT é abertamente assumida e pode, muitas vezes, ser valorizada. A naturalidade com que tal violência é tratada sugere o enraizamento da discriminação contra pessoas LGBT, na cultura escolar. A escola, que deveria ser espaço privilegiado para o exercício da cidadania e da garantia do direito humano à educação, mostra-se como palco para a produção e reiteração das desigualdades constituídas a partir das diferenças identitárias.

Em um contexto no qual a equidade de gênero entre as pessoas não consegue ser garantida, como ocorre no contexto escolar, trajetórias de vítimas de violência e discriminação sexual confundem-se com trajetórias de exclusão escolar. É notório o histórico de abandono escolar daquelas/es que servem de alvo às práticas discriminatórias e violentas, como mostra um dos relatos trazidos pela pesquisa:

Tinha um menino sabe, ele era um menino delicado, você entende? Homem não é assim, não aceita isso. Mas era o jeito dele, não era porque ele era gay e tal, afeminado, ele era uma pessoa assim que, sabe? Ele era completamente 
diferente de um menino, assim, ele não é diferente as atitudes dele, o jeito dele agir, ele não tinha aquele machismo, ele tratava as pessoas mais com clareza. A amizade com os meninos sabe, ele não tinha, porque todo mundo falava que ele era gay e chegou assim a ter um caso assim altamente drástico dentro da sala, ele falou que ia parar de estudar por causa disso. (Grupo focal com alunos, escola pública Rio Branco) - (ABRAMOVAY et al., 2004).

Este ponto é destacado também por Cícera Leite Gomes Barbosa, que, em sua pesquisa "Ouvindo as vozes da homossexualidade: multiculturalismo, educação e suas possibilidades na agência escolar", observou o alto índice de evasão entre estudantes vítimas de discriminação. Em entrevista ao Observatório da Educação, em 2009, ela destacou:

\begin{abstract}
A escola não trabalha a questão das diferenças, do aluno que tem as suas diferenças, tanto físicas, psicológicas e sexuais, quanto de crenças e de cor. Isso faz com que o aluno se sinta diferente e por ser diferente cria-se um estereótipo. Então, eles vão para escola e não são aceitos. Na conversa com os profissionais e alunos percebemos a discriminação. Então, esses alunos abandonam a escola constantemente, tentam ser aceitos em outros espaços, mas acabam não sendo...e assim a vida acadêmica fica cheia de interrupções. Muitos voltam para a escola na Educação de Jovens e Adultos, mas em todas as modalidades eles têm problemas, independente do nível de escolaridade. É igual. Mas a maioria está na EJA, depois de vários anos de repetência e evasão, voltam à noite para a escola, e a discriminação continua (BARBOSA, 2009).
\end{abstract}

Como destacam Souza e Bernardo (2014), a trajetória de uma pessoa travesti ou transexual costuma ser marcada por uma dupla camada de preconceito: primeiro, por sua identidade de gênero e, segundo, por sua colocação, ou falta dela, no mercado de trabalho decorrente da escolaridade incompleta.

Se, por um lado, as violências simbólicas e físicas sofridas pelas pessoas LGBT são muitas vezes naturalizadas no ambiente escolar, não é de admirar que o abandono escolar dessas pessoas seja também pouco problematizado. Discriminadas diariamente nas escolas, lésbicas, gays, bissexuais, travestis e transexuais são empurradas/os para a margem do sistema escolar e têm seu direito à educação, um direito humano, subtraído de modo silencioso, sem que se discuta ou busque caminhos para a manutenção destes grupos na escola (PERES, 2009). Segundo a Associação Brasileira de Lésbicas, Gays, Bissexuais, Travestis e Transexuais (ABGLT), o grupo mais vulnerável é o de travestis e transexuais, cuja estimativa é de que $73 \%$ abandonam o sistema de ensino antes de completar a educação básica (SOUZA \& BERNARDO, 2014). E são pelas situações cotidianas do ambiente escolar que a maioria delas e deles encontram os principais entraves. 
Lilith [aos oito anos] ainda não era travesti e se portava como menino, mas devido aos seus trejeitos femininos sempre era molestada e agredida pelos outros meninos que a humilhavam constantemente. Um dia, após o sinal de retorno do recreio, Lilith dirigiu-se ao banheiro (deixava para ir por último para evitar molestações) e foi atacada por nove meninos que a obrigaram a fazer sexo oral e anal com todos do grupo. Após a experiência da "curra", ficou algum tempo caída no chão, chorando, até ser encontrada pela servente da escola, que a levou até a diretoria, onde fez a queixa e a denúncia dos meninos que a haviam violentado. Após a denúncia, a diretora chamou os meninos envolvidos e constatou que entre eles estavam seu filho e um sobrinho que, em prantos, negavam a participação no episódio. Após alguns dias, a diretora da escola convocou Lilith e seus familiares para promulgar a sua expulsão por "atentado violento ao pudor". Como consequência de negociação entre os familiares e a diretora, foi feita a transferência de Lilith para uma escola particular, mesmo sabendo das condições de pobreza em que vivia sua família e o quão difícil seria arcar com os custos de uma escola particular. Lilith diz ser uma pessoa revoltada e indignada com a experiência vivida na escola e que, muitas vezes, pensou em abandonar os estudos. Constantemente fugia da escola devido às molestações e às agressões dos outros meninos ou ainda por piadas emitidas pelos próprios funcionários da escola. Porém, quando descoberta era obrigada por sua mãe a retornar à escola, mesmo com todas as justificativas que tinha para não voltar. (PERES, 2009).

Banheiros e livros de chamadas aparecem em toda a bibliografia como peças fundamentais de perpetuação de transfobia nas escolas. A organização dos banheiros entre "masculino" e "feminino", tomando-se como base a diferença corporal dos órgãos genitais, impõe um não-lugar para as pessoas travestis e transexuais e as submetem a situações de violência como a descrita acima. Casos de violência física em banheiros são comuns em relatos de pessoas trans de todas as idades e, por isso, é importante que todas as unidades escolares adotem uma política de acolhimentos nesses espaços, deixando que as próprias pessoas travestis e transexuais possam escolher em qual banheiro se sentem mais confortáveis e seguras/os para usar. Nesse mesmo sentido, atividades pedagógicas que se utilizam da oposição de gênero ("meninas de um lado e meninos de outro") devem ser cada vez menos incentivadas, já que não reconhecem a possibilidade de diversidade de pessoas que não se encaixam nos padrões socialmente predeterminados e cria contextos de humilhação e discriminação.

Políticas produzidas com o intuito de reparação dessas desigualdades aos poucos tentaram se delinear, mas têm impactos ainda muito tímidos diante da dimensão do problema a ser enfrentado. Um exemplo que deve ser destacado é a promulgação de leis que garantem o uso de nome social nas escolas, ou seja, que possibilita que estudantes trans sejam chamadas/os pelos nomes escolhidos no processo de mudança corporal e não por aqueles designados em seu nascimento ou registro nos documentos públicos da 
escola. Isso evita, por exemplo, que um estudante recém-chegado na escola e visivelmente masculino seja constrangido em se assumir pelo nome feminino durante hora da chamada ou de entrega de avaliações. Adotar o nome com o qual a pessoa se identifica nas relações cotidianas com ela, além de assumir uma postura de respeito, é agora também diretriz do Conselho Nacional de Combate à Discriminação e Promoção dos Direitos de Lésbicas, Gays, Travestis e Transexuais (BRASIL, 2015).

Em 2007, por meio da resolução n. 33 (BRASIL, 2007), as "pessoas transgêneros" foram incluídas como categoria nas inscrições de alunas/os no Programa Brasil Alfabetizado. O Estado indicava que reconhecia travestis e transexuais como um público potencial aos programas de alfabetização de jovens e adultos. Frente aos relatos de marginalização de pessoas LGBT no sistema escolar, podemos levantar a hipótese de que, afinal, tal demanda se justificaria pela falta de condições de acesso ou de manutenção de tais pessoas no ensino regular, dificuldade esta provocada pelo quadro de discriminação e violência.

Entretanto, ainda que o Estado reconheça a existência deste quadro de discriminação e de suas consequências à população LGBT, parece não haver força suficiente para a implementação de políticas mais incisivas no combate à discriminação contra pessoas travestis e transexuais, ainda mais em uma conjuntura política de ampla resistência ao tema. O tamanho do efeito provocado pela desigualdade de gênero é bastante impreciso e o levantamento de indicadores que possam avaliar quantitativamente o número de estudantes travestis e transexuais expulsos da escola ainda é uma urgente demanda. Enquanto isso, histórias de trajetórias escolares marcadas por violência e abandono se repetem e trazem travestis e transexuais para o gigantesco contingente populacional com 15 anos ou mais, que não teve garantido seu direito à educação básica no Brasil.

\section{Considerações finais}

Práticas de discriminação à população LGBT não são apenas comuns no ambiente escolar, como, inclusive, são abertamente assumidas e muitas vezes valorizadas, como demonstrou a pesquisa de 2004 (ABRAMOWAY et al., 2004). De tal cenário de discriminação e violência, um ciclo de abandono escolar instala-se e afasta travestis e transexuais das salas de aulas. Nesse sentido, o espaço considerado privilegiado para o exercício da cidadania e da garantia do direito humano à educação mostra-se, 
contraditoriamente, como palco para a produção e reiteração das desigualdades. Neste contexto, emerge a necessidade de políticas desenhadas para a garantia do direito à educação de pessoas LGBT e a garantia de seus acessos aos espaços sociais vinculados à elevação de escolaridade.

No que se refere especificamente à Educação de Jovens e Adultos, coloca-se como tarefa o reconhecimento desses sujeitos como sujeitos demandantes da modalidade em que estão excluídos, até mesmo das estatísticas. Em uma perspectiva de uma educação inclusiva, faz-se necessária a ampliação de estudos e produção de novos dados que permitam caracterizar o público LGBT, no que se refere à escolaridade e criar políticas específicas para que aquelas/es que necessitam possam retomar os estudos em condições favoráveis, no âmbito da educação de jovens e adultos. Paralelamente, é imprescindível também que as discriminações de gênero sejam reconhecidas como alvo de intervenções pedagógicas e incluídas no espectro de questões enfrentadas na formação inicial e continuada das/os profissionais da educação.

O que está colocado como desafio político é a criação de condições, para que um grupo historicamente vulnerável, como é o caso da população LGBT, possa ter garantido seu direito humano à escola. E, nesse sentido, destaca-se a necessidade de que os grupos de educadoras/es que lutam pela educação de jovens e adultos aproximem-se cada vez mais dos movimentos que atuam em defesa dos direitos da população LGBT, para que se construa uma proposta articulada de inclusão desse grupo na EJA.

\title{
REFERÊNCIAS BIBLIOGRÁFICAS
}

\author{
ABRAMOVAY, M.; CASTRO, M. G.; SILVA, L. B. da (Org.). Juventude e \\ sexualidade. Brasília: UNESCO, 2004. Disponível em: \\ $<$ http://unesdoc.unesco.org/images/0013/001339/133977por.pdf> Acesso em: \\ 25/04/2016.
}

\begin{abstract}
ABRAMOVAY, M.; CASTRO, M. G.; WAISELFISZ, J. J. Juventudes na escola, sentidos e buscas: Por que frequentam? Brasília: FLACSO - Brasil, OEI, MEC, 2015. Disponível em: <http://flacso.org.br/files/2015/11/LIVROWEB_Juventudes-na-escolasentidos-e-buscas.pdf $>$ Acesso em: 25/04/2016.
\end{abstract}

AÇÃO EDUCATIVA; CARREIRA, D. Informe Brasil: gênero e educação. São Paulo: Ação Educativa, 2011. 
BARBOSA, C. L. G. A escola pública é violadora de direitos das pessoas homossexuais, diz pesquisadora. Entrevista do Observatório da Educação: 03 abr. 2009.

BRASIL. Ministério da Educação. Secretaria de Educação Continuada, Alfabetização, Diversidade e Inclusão. Documento Nacional Preparatório à VI Conferência Internacional de Educação de Adultos. Ministério da Educação/Secretaria de Educação Continuada, Alfabetização, Diversidade e Inclusão. Brasília: MEC, 2016.

BRASIL. Ministério da Educação. Resolução/Fnde/Cd Nº 033, de 03 de julho de 2007. Critérios e procedimentos do Programa Brasil Alfabetizado, 2007.

Conselho Nacional de Combate à Discriminação e Promoção dos Direitos de Lésbicas, Gays, Travestis e Transexuais. Resolução No 12, de 16 de janeiro de 2015.

Sec. Geral da Presidência da República. Marco de Referência da Educação Popular para as Políticas Públicas. Brasília, 2014. Disponível em: $<$ http://conae2014.mec.gov.br/images/pdf/MarcodeReferencia.pdf>. Acesso em: 24/03/2016.

BUTLER, J. Problemas de Gênero: feminismo e subversão da identidade. Rio de Janeiro: Civilização Brasileira, 2003.

CARREIRA, D. Gênero e raça: a EJA como política de ação afirmativa. In: CATELLI JR, R.; HADDAD, S.; RIBEIRO, V. M. (Org.). A EJA em xeque: desafios das políticas de Educação de Jovens e Adultos no século XXI. São Paulo: Global, 2014, p.195-230.

CARVALHO, M. P. de. O fracasso escolar de meninos e meninas: articulações entre gênero e cor/raça. In: MELO, H. P. de; PISCITELLI, A.; MALUF, S. W.; PUGA, V. L. (Org). Olhares Feministas. Brasília: Ministério da Educação, UNESCO, 2004. Disponivel em: <http://www.scielo.br/pdf/cpa/n22/n22a10.pdf >. Acesso em: 19/05/2016.

CONSELHO Nacional de Combate à Discriminação. Brasil sem Homofobia: programa de combate à violência e à discriminação contra GLTB e promoção da cidadania homossexual. Brasília: Ministério da Saúde, 2004.

ESCOURA, M. Girando entre Princesas: performances e contornos de gênero em uma etnografia com crianças. 2012. Dissertação (Mestrado em Antropologia Social) Faculdade de Filosofia, Letras e Ciências Humanas, Universidade de São Paulo, São Paulo, 2012. Disponível em: <http://www.teses.usp.br/teses/disponiveis/8/8134/tde08012013-124856>. Acesso em: 28/05/2015.

FERRARO, A. R. Alfabetização rural no Brasil na perspectiva das relações campocidade e de gênero. Educ. Real., Porto Alegre, v. 37, n. 3, p. 943-967, set./dez. 2012. 
Disponível em: 〈http://www.scielo.br/pdf/edreal/v37n3/13.pdf>. Acesso em: 25/04/2016.

IRELAND, T.; SPEZIA, C. Educação de adultos em retrospectiva: 60 anos de CONFINTEA. Brasília: UNESCO, MEC, 2012.

LOURO, G. L. Mulheres na Sala de Aula. In: DEL PRIORI, M. (Org). História das Mulheres no Brasil. São Paulo: Contexto, 2004.

MAUSS, M. Noções de técnicas corporais. In: Sociologia e Antropologia. São Paulo: Cosac Naify, 2003.

MAZZON, J. A. Relatório Analítico Final: Projeto de estudo sobre ações discriminatórias no âmbito escolar, organizadas de acordo com áreas temáticas, a saber, étnico-racial, gênero, geracional, territorial, necessidades especiais, socioeconômica e orientação sexual. São Paulo: FIPE - Fundação Instituto de Pesquisas Econômicas, 2009.

MEAD, M. Sexo e temperamento. São Paulo: Perspectiva, 2003.

PERES, Wiliam Siqueira. Cenas de exclusões anunciadas: travestis, transexuais, transgêneros e a escola brasileira. In: JUNQUEIRA, R. D. (Org.). Diversidade sexual na educação: problematizações sobre a homofobia nas escolas. Brasília: MEC, Secretaria de Educação Continuada, Alfabetização e Diversidade, UNESCO, 2009. p. 235-263.

OLIVEIRA, R. P. de. Da universalização do ensino fundamental ao desafio da qualidade. Educ. Soc., Campinas, vol. 28, n. 100 - Especial, p. 661-690, out. 2007. Disponível em: 〈http://www.scielo.br/pdf/es/v28n100/a0328100.pdf>. Acesso em: 25/04/2016.

PNAD/IBGE - Instituto Brasileiro de Geografia e Estatística. Indicadores IBGE: Pesquisa Nacional por Amostra de Domicílios Contínua. Rio de Janeiro: IBGE, Coordenação de Trabalho e Rendimento, 2013.

SOUZA, H. A., BERNARDO, M. H. Transexualidade: as consequências do preconceito escolar para a vida profissional. Revista Bagoas, v. 8, n.11. jul./dez., 2014.

SCOTT, J. Gênero: uma categoria útil de análise histórica. In. Educação e Realidade. Porto Alegre, v. 2, n. 16, jul./dez., 1990.

UNESCO. Conferência Internacional de Educação de Adultos (CONFINTEA). Marco de Ação de Belém. Unesco: Brasília, 2010. Disponível em: <http://www.unesco.org/fileadmin/MULTIMEDIA/INSTITUTES/UIL/confintea/pdf/w orking_documents/Belem\%20Framework_Final_ptg.pdf>. Acesso em: 19/05/2016. 
UNESCO. V Conferência Internacional de Educação de Adultos (CONFINTEA). Hamburgo, Alemanha, 1997. Disponível em:

<http://unesdoc.unesco.org/images/0012/001297/129773porb.pdf>. Acesso em: $24 / 03 / 2016$.

Recebido em: 29/03/2016

Aprovado em: 22/05/2016 